\title{
Minimal authorship (of sorts)
}

\author{
Christy Mag Uidhir
}

(C) Springer Science+Business Media B.V. 2010

\begin{abstract}
I propose a minimal account of authorship that specifies the fundamental nature of the author-relation and its minimal domain composition in terms of a three-place causal-intentional relation holding between agents and sort-relative works. I contrast my account with the minimal account tacitly held by most authorship theories, which is a two-place relation holding between agents and works simpliciter. I claim that only my view can ground productive and informative principled distinctions between collective production and collective authorship.
\end{abstract}

Keywords Authorship - Authors · Works · Appropriation · Collaboration · Collective authorship

Most philosophical debates about authorship concern its scope and impact-for what, if anything, and how, if at all, should authorship figure. For such debates to be coherent, the theories involved must agree on what authorship minimally requires. I take most theories counting authorship a matter of consequence ${ }^{1}$ to entail explicitly or implicitly the following:

(1) The author-relation is a two-place relation: $x A y-x$ is an author of $w$, $x$-authored $w, w$ is authored by $x, w$ is $x$-authored.

(2) The author-relation is both causal (real, ostensible, or ersatz) and intentional (actual or virtual).

\footnotetext{
1 For the debate about the per se relevance of authorship see (Foucault 1969; Barthes 1997; Nehamas 1986; Lamarque 2001).

C. Mag Uidhir $(\bowtie)$

City College of New York, NAC 5/144, 160 Convent Avenue, New York, NY 10003, USA

e-mail: cmaguidhir@ccny.cuny.edu
} 
(3) So, the author-relation is a causal-intentional relation between an agent (actual or non-actual) and the substantive products of that agent's intention-directed activities, such that, $x A y$ only if $y$ is the substantive product of an intentiondirected activity for which $x$ is the source. ${ }^{2}$

The above should appear relatively uncontroversial. Things, objects, events, entities, or states of affairs simpliciter cannot be authors or be authored, so the author-relation must be in terms of causal-intentional agency and its substantive products (here on referred to as 'works'). Theories, of course, diverge as to what can permissibly stand in the author-relation. Some leave the domain unrestrictedworks as intentional products simpliciter (Hilpinen 1993). Others narrow the domain so as to exclude 'mere' artifacts (e.g., shovels, baloney sandwiches, gym socks) — works as intentional products prima facie aimed at some uptake (Lamarque 2002; Livingston 2005). ${ }^{3}$ However such theories may restrict the scope of works, they share an account of minimal authorship as a two-place relation between agents and works $(x A w)$ seemingly supported by our commonsense intuitions.

I argue that the above account of minimal authorship and the intuitions informing it are misguided. Minimal authorship in terms of a two-place relation between agents and works is far too broad to be productive or informative in all but the most garden variety of cases and risks incoherence in non-standard cases, especially those involving collective production. Even were we to suppose that commonsense intuitions reliably track singular authorship, they clearly fail to track collective authorship reliably. This failure becomes glaringly obvious for paradigmatic works of collective production (e.g., mass-market comics, movies, songs). As such, authorship concerns for non-standard works cannot be resolved by appealing to intuitions tracking authorship for standard works (Sellors 2007; Meskin 2008).

I claim that in order to have a substantive account of minimal authorship capable of solidly grounding collective authorship claims, we must abandon the two-place relation $x A w$-authorship-of-a-work-in favor of the three-place relation $x A(F w)$ authorship-of-a-work-as-an- $F$ (where $F$ is some work-description). Only authorship as a three-place relation between agents, works, and work-descriptions can underpin crucial and productive distinctions between singularly-authored collectivelyproduced works and collectively-authored collectively-produced works-authorship must be work-description relative.

In Sect. 1, I propose that authorship-of-a-work-as-an- $F$ minimally entails the following for an agent $(A)$, a work $(w)$, and a work-description $(F)$ :

$A$ is an author of $w$ as an $F$ if and only if $A$ is directly responsible, at least in part, for $w$ as an $F$.

In Sect. 2, I argue that collective production need neither entail nor suggest collective authorship. I characterize singularly-authored collectively-produced works as either appropriation cases or commission cases and in Sect. 3 characterize collectively-authored collectively-produced works as either collaborative or

\footnotetext{
2 For accounts of intention-directed actions see (Davidson 1980; Ginet 1990; Bratman 1999).

3 Lamarque (2002) counts works as products for which reception conditions are prima facie constitutive of identity, Livingston (2005) further restricts this in terms of works as expressions.
} 
non-collaborative, thereby rendering tractable otherwise slippery and complex issues of collective authorship. In the end, my view is a substantive and informative account of minimal authorship both flexible and strong enough to be effectively employed in claims about what metaphysical, interpretive, and evaluative roles authorship may play.

Before I begin, however, I must first be clear about the terms I use and the assumptions that I do and do not make. I employ the phrase ' $w$ as an $F$ ' to designate a work under description $F$ or work-description $F$ (e.g., dance, essay, film, jingle, limerick, novel, painting, photograph, poem, print, song, etc.). Though workdescriptions may best be viewed as sortals (Geach 1962; Mackie 1994; Wiggins 2001), ${ }^{4}$ I want 'work' and 'work-description' to be reasonably broad and nontechnical, showing no overt allegiance to any particular metaphysical or semantic view (e.g., works as types or concrete particulars, sorted wholly or in part according to reception or production practices and conventions, or supporting semantic distinctions between 'author' and 'maker', 'designer' or 'producer').

Most importantly, my project doesn't entail anything over and above providing a substantive account of minimal authorship. That is, I do not assume authorship germane for all work-descriptions (Hilpinen 1993) ${ }^{5}$ or that authorship figures in work-identity (Levinson 1990) or work-individuation (Rohrbaugh 2005). ${ }^{6}$ Additionally, I do not assume that authorship constitutively figures for work-interpretation or work-evaluation; I make no claims as to whether authors are non-actual author-constructs (Booth 1961; Levinson 1990; Irwin 2001) rather than actual agents, individual or collective (Hirsch 1967; Stecker 1997; Carroll 2001). I merely designate what I take to be the fundamentally and philosophically salient feature of authorship. By framing my view in this way, I can provide a broadly appealing yet philosophically substantive account of authorship that, when embraced, productively shifts the philosophical landscape.

\section{Minimal authorship}

To be an author of a work under a description is to be directly responsible, at least in part, for that work being under that description (i.e., to be directly responsible for the way in which that work satisfies the conditions for being under that description). So, if I am an author of work $w$ under description $F$, then it had better turn out that I had something to do with $w$ satisfying the conditions for being an $F$. We ought to think conceptual confusion afoot should someone claim that I am the author of a

\footnotetext{
${ }^{4}$ Likewise 'author' may best be viewed as a sort-relative predicate. Kit Fine (2003) argues the same for the predicate 'make'.

5 One could make a case for Hilpinen (1993) arguing for a three-place relation (agents, intentional products (artifacts), sortal descriptions), but his account is best read as a two-place relation (agents, artifacts) for which sortal descriptions broadly construed hold for objects qua artifacts only if the sortal descriptions are mentally represented in the agent's directing intentions (I address this later). Hilpinen's view fundamentally is an account of intentional production (which so construed I would in the main happily endorse) and not an account of authorship.

6 Though I assume work-descriptions as sortals do so figure.
} 
work as a painting but that my intention-directed activities in no way figured in the work coming to satisfy the conditions for being a painting. If works under certain descriptions do have authors, then being an author entails being directly responsible, at least in part, for a work being under such a description. Any account of authorship must capture this.

Assume for the sake of argument and simplicity the following. Let $C$ be the set of all and only those features essential for work-description $F$. $^{7}$ So,

Work $w$ is an $F$ if and only if $w$ possesses the features in $C .^{8}$

From this, the following:

$A$ is the author of $w$ as an $F$ if and only if $A$ is directly responsible, at least in part, for $w$ 's possession of the features in $C$.

Further specified with the following:

For $A$ to be directly responsible, at least in part, for $w$ 's possession of the features in $C$ is for $A$ 's intentions to figure substantively in w's possession of at least one of the features in $C{ }^{9}$

If $w$ is an $F$, then if $A$ is the author of $w$ as an $F$, then $A$ 's intentions must substantively figure in that work being an $F$ (the way in which that work satisfies the conditions for being an $F$ ). For $w$ to be the particular $F$ that it is, is for $w$ to be an $F$ in a particular sort of way (to satisfy the conditions for being an $F$ in virtue of the particular features it possesses). Authorless Fs, if there can be such things, then are works that satisfy the conditions for being an $F$ but works for which no one is directly responsible, at least in part, for the particular way in which the work satisfies those conditions. If $A$ is an author of $w$ as an $F$, then it cannot be the case that $A$ is directly responsible for $w$ being an $F$ but not directly responsible for the particular way in which $w$ is an $F$. So, being the author of $w$ as an $F$ entails being the author of that particular $F$.

Note that I allow for collective/shared intentions (Gilbert 1989; Velleman 1997; Corlett 2001). That is, $A$ can be a single individual or a collection of all and only those individuals that taken jointly, but not alone, satisfy the conditions for being an author. Also note that $A$ 's being the author of $w$ as an $F$ and $B$ 's being the author of $w$ as a $G$ doesn't entail that $A$ and $B$ token the same 'authoring' action-type or that $A$ and $B$ formed the same kind of 'authoring' intention. I assume that there are neither general 'authoring' action-types that must be tokened nor general 'authoring' intentions that must be formed. For instance, being an author of a work as a poem entails being the source of the appropriate sorts of intentions directing the

\footnotetext{
${ }^{7}$ I am not assuming that work-descriptions must have essentialist accounts; I merely employ one for the sake of simplicity. My view should perform equally well for more pluralist or open-ended accounts, just note that work-descriptions with nebulous satisfaction conditions unsurprisingly ought to result in equally nebulous satisfaction conditions for authorship.

${ }^{8}$ I do not target trivially essential/necessary features (i.e., being an object, being a non-minotaur, being [a painting or a marmoset]).

${ }^{9}$ I use the term 'substantively' to mean at least non-trivially and non-accidentally and at most exhaustively or essentially.
} 
appropriate sorts of activities of which the work is a product, the substantive result of which is the satisfaction of the conditions for being a poem. Determining the appropriate sorts of intentions and appropriate sorts of activities first requires determining what it is to be a poem-that's just what it is for authorship to be workdescription relative. For $A$ to be the author of $w$ as an $F$ is for $w$ being an $F$ to result substantively from the appropriate sorts of activities directed by the appropriate sorts of intentions of which $A$ is the source. Any further specification requires first specifying what it is to be an $F$.

\section{Collective production and authorship}

I take there to be two broad classes of authorship: singular and collective.

Singular authorship: Only $A$ is an author of $w$ as an $F$.

A subspecies of which is:

Conjunctive authorship: Only $[A$ and $B \ldots]$ is an author of $w$ as an $F$, but neither $A$ nor $B \ldots$ taken alone is an author of $w$ as an $F .^{10}$

The other broad class is:

Collective authorship: $A$ and $B \ldots$ are authors of $w$ as an $F$.

I suppose that, prima facie, collective authorship entails collective production, and that to be collectively produced just is to be the product of activities with multiple, distinct intentional sources. ${ }^{11}$ Collective production, however, should neither entail nor suggest collective authorship. Most films are collectively produced, and while I suppose that key grips fulfill crucial production roles, key grips are not thereby authors of films. Likewise, many prints are collectively produced, and while I suppose that print technicians and master printmakers play critical production roles for prints, they are not thereby authors of the prints they help produce. We don't discount key grips and print technicians as authors because they do not fill significant production roles - they obviously do. Rather, we regard the activities in which key grips and print technicians engage, though complex and highly skilled, as being broadly directed by - or facilitating those activities directed by - the intentions of others (e.g., film directors, cinematographers, graphic designers, print artists). Of course, while collective production doesn't entail collective authorship, many collectively produced works under certain work-descriptions are collectively authored. Before I

\footnotetext{
${ }^{10}$ For example, consider the painting United States: Most Wanted (1994). There are seemingly only two candidates for authorship of the painting, Vitaly Komar and Alex Melamid. Both Komar and Melamid claim, however, that neither authors the painting; instead, they claim that there is but one author of Most Wanted, which is [Komar and Melamid], the artist team made up of Vitaly Komar and Alex Melamidthe team, not its members taken alone, is the source of the substantively figuring intentions. I want to allow at least in principle for such claims to be true.

11 For my purposes, I do not count as collectively-produced works produced by a single intentional source where that source is some group or collective agent (collective intentions).
} 
address these, I first discuss how best to characterize collectively produced but singularly-authored works.

\subsection{Appropriation cases}

Suppose that I want my work to be an $F$. To bring this about, I might engage in the standard kinds of activities that typically result in the production of a work as an $F$. I also might simply appropriate a pre-existing product of another's effort with regard to those activities. Note that strict replacement in terms of functional equivalence won't do. Appropriation in the sense I employ concerns cases in which I want my work (a) to be an $F$ in virtue of having another $F$ as a proper part or (b) to be an $F$ in virtue of having a $G$ as a proper part.

For example, consider Elaine Sturtevant's work Warhol Flowers (1964), a silkscreen pulled by Sturtevant from the burned (exposed) screen Andy Warhol used to produce silk-screens in his Flowers series. Suppose that prints pulled from burned Warhol screens are Warhol prints. This, however, doesn't entail that Warhol Flowers is a Warhol print (where 'Warhol print' refers to prints authored by Warhol). Warhol Flowers has a Warhol print as a proper part, but Warhol Flowers is not a Warhol print-that's the point. To be sure, the production history of Warhol Flowers constitutively involves the products of Warhol's activities but only as a substantive result of Sturtevant's intentions. That Warhol Flowers has a Warhol print as a proper part doesn't entail that Warhol is directly or even indirectly responsible for Warhol Flowers. Though Warhol Flowers is a silk-screen in the same way Warhol's Flowers is a silk-screen-pulled from the same screen, a screen produced by Warhol and not Sturtevant-Warhol's intentions do not figure at all, let alone figure substantively, for Warhol Flowers. Only Sturtevant's substantively figure, so Warhol cannot be an author of Warhol Flowers. Similarly, consider Richard Prince's rather aptly titled photograph By Richard Prince, A Photograph of Brooke Shields by Garry Gross (1983), which features a 1975 Garry Gross photograph of a nude, 10-year old Brooke Shields. Though the photograph By Richard Prince... has a proper part a photograph for which Gross's intentions substantively figured, Gross's intentions do not figure at all for By Richard Prince, so Gross cannot be an author of By Richard Prince, A Photograph of Brooke Shields by Garry Gross-again, that's the point. ${ }^{12}$

While these are cases in which a work is an $F$ in virtue of the appropriation of an $F$ as a proper part, many appropriation cases involve a work being under a certain description $(F)$ in virtue of the appropriation of a work under a different description $(G)$ as a proper part, where $w$ as an $F$ having a $G$ as a proper part doesn't entail that $w$ is both an $F$ and a $G$. For example, Marcel Duchamp's Bottle Rack (1914) is a readymade sculpture with a bottle rack as a proper part, but Bottle Rack (1914) is not a bottle rack. So too for Mike Bidlo's Not Duchamp's Bottle Rack 1914 (2000). ${ }^{13}$ Similarly, Tobias Wong's This is a Lamp (2001) is a Duchamp-Magritte

\footnotetext{
12 Consider also Tobias Wong's Warhol Gift Wrap (2002)_for around \$20,000 Tobias Wong will wrap your holiday gifts using original Warhol screenprints.

13 Both of course could be used as bottle racks in virtue of having bottle racks as a proper parts.
} 
inspired "readydesigned" sculpture having as a proper part a lamp converted from a Phillippe Starck Bubble Club Chair, but This is a Lamp is not a Starck chair (or a chair at all). This is a Lamp has as a Starck chair as a constitutive component only as a substantive result of Wong's intentions-Starck's intentions do not figure at all for This is a Lamp. So, Starck cannot be an author of This is a Lamp.

On my view, appropriation cases involving author-relevant work-descriptions entail the following for collective production cases.

Let $A \neq B ; P=$ the products substantively resulting from the specified agent's activities; $I=$ that agent's intentions directing those activities in $P$.

(1) $P_{A}$ and $P_{B}$ are constitutive of $w$ as an $F$.

(2) $A$ is an author of $w$ as an $F$.

(3) $P_{B}$ is constitutive of $w$ as an $F$ only as a substantive result of $I_{A}$.

(4) $B$ is neither directly nor indirectly responsible for $w$ being an $F$.

(5) $I_{B}$ doesn't figure in $w$ being an $F$.

(6) So, $B$ is not an author of $w$ as an $F$.

Note that appropriation, broadly construed, captures cases of adaptation (e.g., novels into films, films into novels), tributes, homages, or covers, as well as the relationship between works under performance-relevant descriptions and performances of works under such descriptions (e.g., playwrights and composers aren't ipso facto authors of theatrical and musical performances of their work).

That appropriation cases involve collective production ought not thereby entail or even suggest that appropriation cases are collective authorship cases. Most importantly, note that my account of minimal authorship clearly shows (pace Irvin 2005) that strict appropriation cases shouldn't be philosophically troublesome for authorship. Appropriation cases may be worrisome for all sorts of reasons-artistic (e.g., originality and creativity concerns), moral (e.g., appropriation as theft), and legal (e.g., copyright and fair-use laws) — but these are clearly concerns over and above minimal authorship.

\subsection{Commission cases}

Suppose that I want my work to be an $F$. To bring this about, I might engage in the standard kinds of activities that typically result in the production of a work as an $F$. I also might commission others to engage in such activities on my behalf (perhaps I lack the skill necessary to achieve the desired result or I might just be too busy or lazy to do it myself). The production history of $w$ as an $F$ then contains activities directed by the intentions of someone other than myself, and so in such cases, collective production might yield collective authorship - unlike for appropriation cases, production credit looks salient for commission cases. Perhaps then there is some degree threshold for production credit that, if crossed, is sufficient for authorship. On my view, no amount or degree of production involvement is itself sufficient for authorship. To be an author of $w$ as an $F$ is to be directly responsible for $w$ being an $F$; nothing less can be sufficient. Commission cases, while cases of collective production, are not cases of collective authorship. Commission cases, however, importantly differ from appropriation cases in that appropriation cases 
involve neither direct nor indirect responsibility while commission cases involve indirect but not direct responsibility.

For example, most printmaking techniques and practices are labor-intensive and disastrously unpredictable in less than skilled hands, and so artists often commission master printmakers to pull the desired number of prints for an edition. ${ }^{14}$ In such cases, print technicians are not the authors of the prints they produce; they may merely print from a provided plate, or according to a provided master proof, or simply according to a set of instructions provided by the print artist, who often demands to see multiple state proofs before final approval is given. Of course, the printer's intentions figure in virtue of directing the appropriate sorts of production activities, their intentions substantively figure only as proxy for the artist's intentions. This holds even in cases where the production is best described as collaborative. For example, Chuck Close worked with the printers Robert Blanton, Thomas Little, and Joseph Stauber from the silkscreen studio Brand X to produce Self-Portrait (1995), a silk-screen featuring an image from one of Close's selfportrait paintings. Given Close's multi-colored grid-style paintings and the demands of multi-layered screenprinting (Self-Portrait is an 80-color silk-screen), the production demands on the printers was monumental, both mentally and physically intensive (Sultan 2003). This alone, however, neither entails nor suggests that the Brand-X printers are authors of Self-Portrait. While Close and the Brand-X printers collaborated with respect to the particular production processes, neither collective nor collaborative production entails collective or collaborative authorship. Close alone determined the image, the color system, the scale, the medium, the support, and the edition size- the collaborative production effort was entirely devoted to realizing Close's intentions regarding those features. As such, Self-Portrait is a Chuck Close screenprint of a Chuck Close painting of Chuck Close. To be sure, printing/production credit goes to the Brand-X printers, but authorship goes to Close and Close alone. ${ }^{15}$

Commission cases, unlike appropriation cases, entail at least a minimal relation to the work as an $F$, but the relation is not an author-relation. ${ }^{16}$ So, on my view, commission cases involving author-relevant work-descriptions entail the following:

(1) $P_{A}$ and $P_{B}$ are constitutive of $w$ as an $F$.

(2) $A$ is an author of $w$ as an $F$.

(3) $P_{B}$ is constitutive components of $w$ as an $F$ only as a substantive result of $I_{A}$.

(4) $I_{B}$ substantively figures only as a proxy for $I_{A}$.

\footnotetext{
${ }^{14}$ While master printmakers themselves may also be print artists (e.g., Robert Blackburn) or be sought for collaborative reasons (which I discuss next), I am currently concerned only with cases in which they are commissioned for their printmaking ability alone.

15 In a telling statement, master printer Kathan Brown of Crown Point Press had this to say about working with Close on the demanding and often thought impossible to produce Keith/Mezzotint (1972)_ Close's first print as a professional artist. "Chuck had specific reasons for doing the mezzotint that were of a particular time and place. All of our successes came out of trying to satisfy his needs" (Sultan 2003, p. 52).

16 Notice that none of this requires invoking creative/non-creative distinctions (e.g., only Close can be an author because only Close's intentions are creative intentions). While one may choose to connect creativity with authorship (e.g., Gaut and Livingston 2003), minimal authorship needn't require it.
} 
(5) $B$ is only indirectly responsible for $w$ being an $F$.

(6) So, $B$ is not an author of $w$ as an $F^{17}$

Note that commission cases, broadly construed, capture the relationship between artists and their assistants (e.g., Dale Chihuly and his team of glass-blowers, Jeff Koons and his army of assistants), print artists and master printers (e.g., Robert Rauschenberg and Robert Blackburn, Frank Stella and Kenneth Tyler), designers and manufacturers (e.g., Phillippe Starck and Aprilia motorcycles, Jonathan Ive and Apple computers), and artists and curators (e.g., Keith Haring and Henry Geldzahler).

Most importantly, on my account, degree of production involvement doesn't matter for authorship. For instance, should I properly execute the instructions contained in Sol LeWitt's Plan for Wall Drawing (1969), then I have made a LeWitt wall drawing - a wall drawing for which only Sol LeWitt is an author. ${ }^{18}$ I can't be an author merely by following instructions. This suggests that commission cases may often involve production roles for which the activities fulfilling those roles needn't be informed by work-descriptions; that is, the intentions directing the activities of those commissioned needn't be informed by what it is for a work to be an $F$ (e.g., the activities fulfilling the production roles needn't be directed by the intention that the work satisfy the conditions for being an $F){ }^{19}$

\section{$2.3 F$-Informed production}

Suppose that Roy Lichtenstein had his graduate students in the art department at Rutgers University physically paint Image Duplicator (1963). Lichtenstein remains the sole author despite this (and despite Image Duplicator featuring an appropriated image from a panel of an $X$-men comic illustrated by Jack Kirby). Notice that if those students were instructed to fill in the Ben-Day Dots, then they needn't also have known, in order to do the work asked of them, anything about pop-art, comic books, Jack Kirby, Benjamin Day, or have even understood the title Image Duplicator. So, while Image Duplicator may have been collectively produced, most certainly Image Duplicator was not collectively authored. Furthermore, sometimes withholding certain information from those employed in the production better promotes the desired result. That is, perhaps in some cases, the less known by those employed in the production about how the products of their activities figure, the less

\footnotetext{
17 This is flexible enough to support a claim that $A$ 's intentions are the "sufficiently controlling" intentions (Gaut 1997) or the claim that only A's intentions must survive certain relevant counterfactual analyses (Inge 2001).

18 LeWitt's wall drawings were intended to be multiple and were often physically drawn not by Lewitt but by his assistants, gallery staff, or even untrained volunteers off the street.

19 I do not claim (pace Hilpinen 1993) that all work-descriptions (let alone all author-relevant workdescriptions) are such that $A$ 's intentions substantively figure for $w$ being an $F$ only if $A$ 's intentions mentally represent $F$.
} 
likely their activities will stray from the manner in which the work was intended to satisfy the work-description. ${ }^{20}$

Given this, we ought to expect collective production to move toward collective authorship when the constitutive features of $w$ as an $F$ substantively result from activities directed by $F$-informed intentions. Suppose that for work-description $F, w$ is an $F$ only if $w$ satisfies the conditions for being an $F$ as a substantive result of activities directed by intentions mentally representing $F$ (entailing possession and employment of the $F$-concept). In such cases, lacking the $F$-concept precludes being an author of a work as an $F$, no matter the degree of production involvement. This suggests that an informative distinction can be made between collective production and collective authorship, especially should one assume prevalent author-relevant work-descriptions for which intentions so informed are necessary.

Assume for the sake of argument, the following:

(1) Only $P_{A}$ and $P_{B}$ are constitutive of $w$ as an $F$.

(2) $F$ is an author-relevant work-description.

(3) $A$ is an author of $w$ as an $F$.

(4) $P_{A}$ is constitutive of $w$ as an $F$ if and only if $I_{A}$ is $F$-informed.

Then, prima facie

(5) If $I_{B}$ being $F$-informed is neither necessary nor sufficient for $P_{B}$ being constitutive of $w$ as an $F$, then $B$ is not an author of $w$ as an $F$ (even in cases where $P_{B}$ requires $I_{B}$ to be $F$-informed).

In appropriation cases, $I_{B}$ bears no relation to $I_{A}$, and in commission cases, $I_{B}$ bears only a proxy relation to $I_{A}$. Moving from collective production to collective (collaborative) authorship then should have nothing to do with degree of production involvement and everything to do with how the intentions involved in the collective production relate both to the work-description and to one another. ${ }^{21}$

\section{Collective authorship}

I take collective authorship prima facie to come in two varieties: collaborative and non-collaborative. Since on my view, authorship is work-description relative, we might expect some work-descriptions to be more or less supportive of collaborative authorship than others. Recall my minimal account of authorship. Assume for the sake of argument, the following. Let $C$ be the class of all and only those features essential for something's being an $F$ and let $C=\left\{f_{1}, f_{2}\right\}$.

\footnotetext{
${ }^{20}$ For example, Frankie Laine was commissioned to sing the theme song for the Mel Brooks movie Blazing Saddles (1974), but no one told him that the movie was a comedy rather than a serious western, and so his performance was achingly earnest, which only added to the film's comedic value.

21 Note that Hilpinen (1993) cannot make this distinction since he claims the author-relation is a bringinto-existence relation, leading him to conflate collective production with collective authorship, and therefore only able to make a distinction between different kinds of authors (e.g., primary authors-those with intentions mentally representing $F$-and secondary authors-those merely involved in the production of $w$ as an $F$ ). This clearly is far too broad.
} 
A work $w$ is an $F$ if and only if $w$ possesses $\left[f_{1}\right.$ and $\left.f_{2}\right]$.

From this, the following:

$A$ is the author of $w$ as an $F$ if and only if $A$ is directly responsible, at least in part, for $w$ 's possession of the features in $C$.

Further specified with the following:

For $A$ to be directly responsible, at least in part, for $w$ 's possession of the features in $C$ is for $A$ 's intentions to figure substantively in $w$ 's possession of $f_{1}$ or $w$ 's possession of $f_{2}$.

With this in mind, I propose the following account of collective authorship.

\subsection{Non-collaborative collective authorship}

Assume that $F$ is an author-relevant work-description for which $f_{1}$ and $f_{2}$ can be independently satisfied, and let $P_{A}$ satisfy $f_{1}$ and $P_{B}$ satisfy $f_{2}$.

(1) Only $P_{A}$ and $P_{B}$ are constitutive of $w$ as an $F$ (Collective Production).

(2) Only $I_{A}$ substantively figures in $P_{A}$ being constitutive of $w$ as an $F$.

(3) Only $I_{B}$ substantively figures in $P_{B}$ being constitutive of $w$ as an $F$.

(4) It is not the case that $P_{A}$ if or only if $P_{B}$.

(5) So, $A$ is an author of $w$ as an $F$ and $B$ is an author of $w$ as an $F$ (NonCollaborative Collective Authorship).

Suppose, however, that $f_{1}$ and $f_{2}$ have a dependence relation such that $w$ possesses $f_{2}$ only if $w$ possesses $f_{1}$. The notion of collaboration itself looks to entail some sort of dependence relation between the intentions directing the activities of those collaborating and their products, and this ought to be reflected in any account of collaborative authorship. That is, collaborations are joint efforts; what one does affects and informs what the other does.

\subsection{Collaborative collective authorship}

Assume that $F$ is an author-relevant work-description for which $\left[f_{1}\right.$ if or only if and $f_{2}$ ], and let $P_{A}$ satisfy $f_{1}$ and $P_{B}$ satisfy $f_{2}$.

(1) Only $P_{A}$ and $P_{B}$ are constitutive of $w$ as an $F$ (Collective Production).

(2) It is the case that $P_{A}$ if or only if $P_{B}$.

(3) So, $I_{A}$ substantively figures in $P_{A}$ being constitutive of $w$ as an $F$ if or only if $I_{B}$ substantively figures in $P_{B}$ being constitutive of $w$ as an $F$.

(4) So, $A$ is an author of $w$ as an $F$ if or only if $B$ is an author of $w$ as an $F$ (Collaborative Collective Authorship).

Non-uniform collaborative authorship is then collective authorship featuring a one-way dependence relation between authors (their products, activities, intentions) $-B$ is directly responsible for $w$ as an $F$ only if $A$ is directly responsible for $w$ as an $F$. Uniform collaborative authorship is then collective authorship featuring a 
two-way dependence relation between authors $-A$ is directly responsible for $w$ as an $F$ if and only if $B$ is directly responsible for $w$ as an $F$.

Of course, we might reasonably think that most author-relevant work-descriptions are such that works cannot discretely possess the constitutive elements for that work-description. Presumably for most visual, literary, and musical work-descriptions, images, words, and sounds simpliciter don't matter; rather images, words, and sounds matter only when considered relationally (e.g., in terms of their juxtaposition, sequencing, or service to some work-description governed narrative, semantic, or aesthetic uptake). ${ }^{22}$ While I suspect that author-relevant workdescriptions prima facie preclude non-collaborative collective authorship, I nevertheless want my view at least in principle to allow for it.

\subsection{Primary and secondary authorship}

The distinction between primary and secondary authorship can be coherent and informative only relative to the kind of collective authorship in play. That is, for non-collaborative collective authorship, being a primary or secondary author may just be a matter of degree of contribution, fleshed out either in terms of degree to which intentions substantively figure or degree of salience of the features for which the intentions substantively figure. Collaborative collective authorship, however, suggests that primary and secondary authorship may be a matter of position in the dependence relation. That is,

$A$ is a primary author and $B$ is a secondary author if and only if a) $B$ is an author only if $A$ is an author and b) it is not the case that $A$ is an author only if $B$ is an author.

Moreover, truly uniform and equal collaborations should have no primary or secondary authors (at least in terms of the dependence relation) since truly equal collaborations result in mutually dependent authorship. Again, to be the author of $w$ as an $F$ is to be directly responsible for $w$ being an $F$, and some $F$ s may be such that the required conditions bear a dependence relation to one another, and so we ought to expect this dependence relation to carry over for those directly responsible for the way in which the work satisfies those conditions. ${ }^{23}$

Determining the work-description then allows for determining whom, if anyone, is directly responsible, at least in part, for the work being under that description. Moreover, given that some author-relevant work-descriptions may be either supportive of or resistant to non-collaborative collective authorship, determining

\footnotetext{
${ }^{22}$ Scott McCloud (1994) has such a view about comics-the fundamental constituent of comics aren't images, but paneled images where paneling entails juxtaposition according to a sequence. For criticisms of this view, see Meskin (2005) and Hyman and Pratt (2005).

23 This can inform the following putatively problematic cases: (i) posthumous authoring (e.g., $B$ completing the late A's unfinished novel), (ii) the role of editors (Inge 2001; Stillinger 1991), and (iii) withdrawn or disowned authorship (e.g., Alan Smithee/Cordwainer Bird cases). Also, in certain disowning cases, we might regard the collectively-produced work in question as still collectively authored but characterize the collective authorship as non-collaborative, indicating that the intention-directed activities of the authors are independent from or contrary to one another.
} 
authorship must be hostage to determining the satisfaction conditions for the relevant work-description. As such, non-empirical difficulties in determining authorship-of-a-work-as-an- $F$ suggests that the source of the difficulty firmly rests with the account of the work-description in question; either the work-description itself is in principle resistant to authorship or the provided account of that workdescription may itself be unworkable. Works under elusive or fractious workdescriptions (e.g. cinema) are ipso facto works for which authorship is elusive or fractious (e.g., cinematic authorship). ${ }^{24}$

\section{Conclusion}

If minimal authorship is authorship of works simpliciter, then being an author of a work entails being responsible for that work being the way it is. The notion of works simpliciter, however, is glaringly uninformative as to which way matters, which features prima facie demand reception, or for which sorts of reception conditions are works author-relevant. Being a work simpliciter matters only because works are constitutive of authorship's domain; that is, they are the kinds of things that can permissibly stand in the author-relation, and this fact alone cannot ground a productive account of minimal authorship.

For example, when authorship is held to be a two-place relation between agents and works simpliciter, issues in cinematic authorship appear intractable precisely because authorship as a two-place relation, when faced with problematic issues in collective production, simply and incorrectly translate those into problematic issues of collective authorship. Under such a rubric, directors, producers, screenwriters, cinematographers, editors, actors, score composers all intuitively appear to be candidates for authorship merely because they all intuitively appear to be playing important, if not essential, production roles. This becomes further complicated given that those production roles above are often highly complex and dependent on one another. $^{25}$

\footnotetext{
${ }^{24}$ I suppose that art and authorship (author and artist, work and artwork) may be intimately connected, and so I suppose that any theory of authorship at least ought to be consistent with there being such a connection. If art is an author-relevant work-description and artists merely authors of works as art, then authorship concerns for artworks appear captive to the myriad disputes about the nature of art. Minimal authorship, however, needn't be hostage to the peculiarities of art theory. If being art is not a workdescription (e.g., adjectival rather than sortal), then artist and author can in principle come apart, and my view at least allows for there to be such a separation. To do otherwise is either to illicitly build into minimal authorship some otherwise peripheral authorship claim or to explicitly or implicitly claim that art theory ought to inform minimal authorship itself. Neither are palatable options, and so accounts of authorship largely motivated by art-theoretic concerns should be to that extent found prima facie suspect.

25 Producers constrain directors (e.g., The Godfather has a 3-h runtime because supposedly producer Robert Evans, after seeing Coppola's first cut, told him to make it an hour longer to give it a more "epic" feel). Films may radically depart from the written source material (e.g., The Shining, the film directed by Stanley Kubrick and The Shining, the novel written by Stephen King). A final studio edit may be radically different than what the director and others had envisioned (e.g., Brazil (1985) directed by Terry Gilliam was drastically re-edited by Universal studio executives from a 142-min film with a dark ending to a 94min film with a happy ending).
} 
As I have argued, however, collective production, no matter how highly complex, fractious, and interdependent, need neither entail nor suggest collective authorship. By making authorship work-description relative, whether someone stands in an author-relation to a work depends on the designated work-description governing the author-relation. Work-descriptions inform us over what features authorship can range, so we need then only figure out who (singular or plural, individual or group, actual or constructed) is directly responsible, at least in part, for the work having those features. So, if cinematic works have authors, then determining cinematic authorship first requires having a robust and workable notion of cinema. Should we appear to have a workable and robust account of cinema only to find cinematic authorship remains as fractious and elusive as before, then either the account of cinema in play isn't so workable after all or cinema isn't an author-relevant workdescription (or is at least in principle resistant to authorship).

This shows that theories predicated on authorship of works simpliciter rely on the brute requisition of intuitions in model work-description cases for use in non-model cases, which unsurprisingly has less than desirable results squarely because commonsense intuitions about authorship are fecund only with respect to model work-descriptions. That is, commonsense intuitions about authorship are in the main reliable in garden-variety cases only because garden-variety cases involve gardenvariety work-descriptions, i.e., work-descriptions for which in the main we have already secured robustly informative and productive accounts. My account of minimal authorship doesn't rebuke commonsense intuitions. Instead, it shows that the scope of commonsense intuitions need only be narrowed accordingly (commonplace work-descriptions). ${ }^{26}$ Moreover, minimal authorship being workdescription relative doesn't entail that settling authorship issues requires exhaustive accounts of work-descriptions. Presumably, many work-descriptions lack complete accounts but nevertheless may be substantial enough to settle authorship issues for that work-description. The prevalence of such work-descriptions, of course, may depend on the reach and import assigned to the practices and conventions surrounding those work-descriptions. Unsurprisingly then, for debates about the robust philosophical work required of authors to be coherent and productive, the principal philosophical focus must shift to work-descriptions.

Acknowledgements The core idea of this paper came from lengthy conversations about authorship I had with Aaron Meskin, Roy T. Cook, and Marcus Rossberg, and as such, I owe a special thanks to these three. I must also thank Robert Stecker for his helpful suggestions on earlier drafts.

\section{References}

Barthes, R. (1997). The death of the author. Image-music-text. New York: Hill and Wang.

Booth, W. (1961). The rhetoric of fiction. University of Chicago Press.

Bratman, M. (1999). Intentions, plans, and practical reason. Stanford, CA: CSLI Publications.

Carroll, N. (2001). Beyond aesthetics: Philosophical essays. Cambridge University Press.

\footnotetext{
${ }^{26}$ In fact, theories precluding work-description relative authorship ipso facto undercut, rather than reinforce, our commonsense intuitions. We also needn't resort to pluralism for the author concept (e.g., standard authorship, non-standard authorship, authorship*).
} 
Corlett, J. A. (2001). Collective moral responsibility. Journal of Social Philosophy, 32, 573-584.

Davidson, D. (1980). Essays on actions and events. Oxford: Claredon Press.

Foucault, M. (1969). What is an author? Reprinted in 2001, W. Irwin (Ed.), The death and resurrection of the author? London: Greenwood Press.

Gaut, B. (1997). Film authorship and collaboration. In R. Allen \& M. Smith (Eds.), Film theory and philosophy. Oxford: Oxford University Press.

Gaut, B., \& Livingston, P. (2003). The creation of art: New essays in philosophical aesthetics. Cambridge, UK: Cambridge University Press.

Geach, P. (1962). Reference and generality: An examination of some medieval and modern theories. Ithaca: Cornell University Press.

Gilbert, M. (1989). On social facts. New York: Routledge.

Ginet, C. (1990). On action. Cambridge: Cambridge University Press.

Hilpinen, R. (1993). Authors and artifacts. Proceedings of the Aristotelian Society, 93, 155-178.

Hirsch, E. (1967). Validity in interpretation. New Haven, CT: Yale University Press.

Hyman, G., \& Pratt, H. (2005). What are comics? In D. Goldblatt \& L. Brown (Eds.), A reader in the philosophy of the arts. Upper Saddle River, NJ: Pearson Education, Inc.

Inge, M. T. (2001). Collaboration and concepts of authorship. PMLA, 116, 623-630.

Irvin, S. (2005). Appropriation and authorship in contemporary art. British Journal of Aesthetics, 45, 123-137.

Irwin, W. (2001). Intentionalism and author constructs. In W. Irwin (Ed.), The death and resurrection of the author? London: Greenwood Press.

Lamarque, P. (2001). The death of the author: An analytical autopsy. In W. Irwin (Ed.), The death and resurrection of the author? London: Greenwood Press.

Lamarque, P. (2002). Work and object. Proceedings of the Aristotelian Society, 102, 141-162.

Levinson, J. (1990). Music, art, and metaphysics. Ithaca: Cornell University Press.

Livingston, P. (2005). Art and intention. Oxford: Oxford University Press.

Mackie, P. (1994). Sortal concepts and essential properties. Philosophical Quarterly, 44, 311-333.

McCloud, S. (1994). Understanding comics: The invisible art. New York: HarperCollins Publishers.

Meskin, A. (2005). Defining comics? Journal of Aesthetics and Art Criticism, 65, 369-379.

Meskin, A. (2008). Authorship. In P. Livingston \& C. Plantinga (Eds.), Routledge companion to philosophy and film. London: Routledge.

Nehamas, A. (1986). What an author is. Journal of Philosophy, 83, 685-691.

Rohrbaugh, G. (2005). I could have done that. British Journal of Aesthetics, 45, 209-228.

Sellors, C. P. (2007). Collective authorship in film. Journal of Aesthetics and Art Criticism, 65, 263-271.

Stecker, R. (1997). Artworks: Definition, meaning, value. Pennsylvania: Pennsylvania State University Press.

Stillinger, J. (1991). Multiple authorship and the myth of solitary genius. Oxford: Oxford University Press.

Sultan, T. (2003). Chuck close prints: Process and collaboration. Princeton, NJ: Princeton University Press.

Velleman, J. D. (1997). How to share an intention. Philosophy and Phenomenological Research, 57, 29-50.

Wiggins, D. (2001). Sameness and substance renewed. Cambridge: Cambridge University Press. 